\title{
Nonlinear Shear Buckling Parametric Finite-Element Analysis of Corrugated Steel Webs
}

\author{
Zhiquan Wen ${ }^{1} \&$ Wenlong Wei ${ }^{1}$ \\ ${ }^{1}$ School of Civil Engineering and Architecture, Chongqing Jiaotong University, Chongqing, China \\ Correspondence: Wei Wenlong, School of Civil Engineering and Architecture, Chongqing Jiaotong University, \\ Chongqing 400074, China. Tel: 86-158-2331-7369. E-mail: 420438061@qq.com
}

Received: April 5, $2014 \quad$ Accepted: June 10, $2014 \quad$ Online Published: June 30, 2014

doi:10.5539/mas.v8n4p223 URL: http://dx.doi.org/10.5539/mas.v8n4p223

\begin{abstract}
The corrugated steel web of prestressed concrete box-girder with corrugated steel webs is in pure shear stress state. The shear-resistant capacity of the corrugated steel web is not determined by the shear strength of steel web, but controlled by the shear buckling strength of steel web. The shear buckling mode and ultimate shear capacity of corrugated steel webs are analyzed by nonlinear finite elements method. The corrugated webs are simulated by 8-node structure shell element. The simulation was done for the defect of corrugated steel web with uniform imperfections mode method, and the defects were included in the material nonlinearity and geometric nonlinearity. On this basis, the influences of corrugation configuration, the overall profile dimensions and steel thickness of corrugated webs on ultimate shear buckling load and buckling mode are investigated.
\end{abstract}

Keywords: bridge engineering, corrugated steel webs, shear buckling, nonlinear, influencing factor

\section{Introduction}

Bridge with corrugated steel webs is a kind of composite-structure of steel and concrete using the corrugated steel webs instead of concrete webs for conventional prestressed concrete box girders. This structure is characterized by reduction of dead weight of main girder, improvement of prestressed efficiency of concrete girder and reduction of on-site work and construction cost. Because of its fast construction, light weight, good ability of span, aesthetic appearance etc, prestressed concrete composite box-girder bridge with corrugated steel webs become more and more popular recent years. Since its appearance, this bridge was investigated and widely used in France, Japanese etc. However, as the theoretical research progressed, prestressed concrete composite box-girder bridge with corrugated steel webs shows a good tendency of development and variable cross-section and large span are adopted gradually in its application.

The composite box girder with corrugated steel webs is a new structure applying external prestressing technique to bridge construction. Compared with normal concrete box girder bridges, in addition to completely avoid the web cracking, this structure has many other advantages, such as force definite, lighter weight, beautiful appearance, and convenient for construction. It is expected that this structure will be strongly promoted and widely used for engineering practice. When the composite box girder with corrugated steel webs bears load, the corrugated steel webs are almost in pure shear stress state. Generally speaking, the design of the composite box girder with corrugated steel webs is mainly controlled by shear buckling failure, so its shear buckling performance is extensively studied. Therefore, how to determine buckling mode and buckling load of the corrugated steel web in shear loads is an essential issue in the study of such structures.

Analysis of corrugated steel web to ultimate shear buckling load and buckling mode with the linear theory of small deflection just gets the branch points of buckling load. The elastic branch points of corrugated steel webs can be obtained by buckling analysis of ideal structures, while the actual structure inevitably exists initial defects, and such defects may induce corrugated steel webs to shift from the ideal branch points of buckling modes to the extreme branch points of buckling modes. It is clearly that the linear theory of small deflection unable to consider the impact of the structure of the initial geometric imperfections, but also unable to consider the impact of the material nonlinearity and geometric nonlinearity, and cannot describe the load and the displacement of the structure in the whole process performance. From this perspective, in order to more realistically reflect the actual structure stress state, the only way to analyze the structure is to use the nonlinear theory of large deflection, considering the material nonlinearity and geometric nonlinearity in the whole process. 
In this paper, the influences of different factors, such as the web thickness, the corrugation angle, the width of horizontal plate, the corrugation depth and the height of the corrugated steel web, etc, on the nonlinear shear buckling property of corrugated steel web are studied by finite element analysis. And initial deformation of corrugated steel web is considered in the finite element model. It will be the innovations of this paper.

\section{Finite Element Model}

In this paper, the eight-node thin-shell element of ANSYS was used to simulate the corrugated steel webs. Each node in the unit has six degrees of freedom. A typical finite element model is shown in Figure 1. In solving nonlinear equations, arc length method is adopted in the finite element model. In addition, it should make an investigation on the choice of element meshes. Through extensive analysis, finite element model of this paper can sufficiently ensure the accuracy of the purpose of this study.

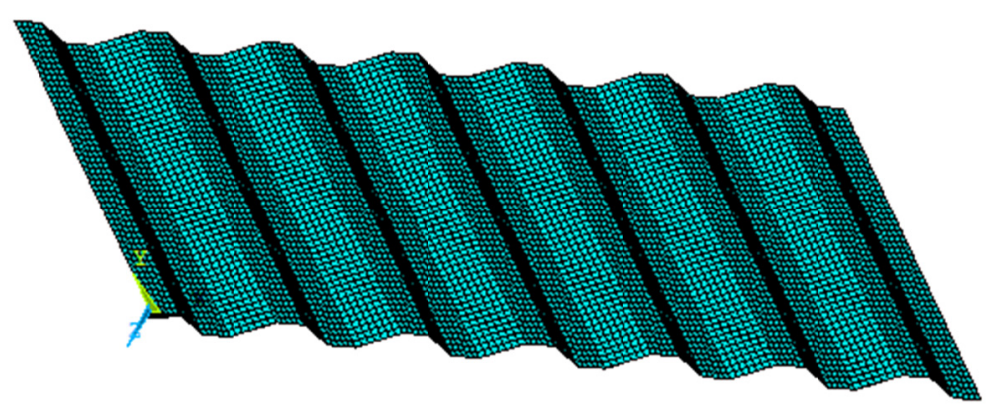

Figure 1. Finite Element model

The finite element model considers the impact of structural defects in the initial geometry and considers the impact of the material nonlinearity and geometric nonlinearity. On the basis of it, the study was done on the influences of corrugation configuration and the overall profile dimensions of the corrugated web on the ultimate shear buckling bearing capacity of the corrugated web and buckling mode for providing the reference to calculation of the similar bridge.

In the course of the actual stress state, corrugated steel webs will exist inevitably certain degree of initial deformation. Namely corrugated steel webs show incomplete rule waveform shape. Such initial imperfections can be called the wave size imperfections. The corrugation configuration imperfections are simulated by uniform imperfections mode method. The first buckling mode of the structure is determined by solving buckling eigenvalue of the structure. According to the first buckling mode of the structure, the deformation of the structure will be in a state of the lowest special potential energy. Therefore, in the initial stage of loading, the actual structure exists a deformation tendency in accordance with the first buckling mode. You can imagine that if the imperfection pattern of the structure coincided with the structure of the first buckling mode, which will undoubtedly have the most adverse impact on the mechanical behavior of the structure. Therefore, in this paper, distribution of the initial defects of the structure is simulated by the first buckling mode of the perfect structure. And then the first buckling mode which is multiplied by a certain proportional coefficient is added to the structure. In this paper, the proportional coefficient of the finite element model is 0.017 .

\section{Influencing Factors of the Shear Capacity and Parametric Analysis}

The ultimate shear buckling load and buckling mode may be influenced by many factors. In order to keep this paper more concise, we shall pay attention on the influences of the parameters in geometry aspect. In all of the following models, the length of steel webs remain unchanged $(\mathrm{L}=11.82 \mathrm{~m})$. The geometric parameters are listed below (it is illustrated by Figure 2):

1) the web thickness (t);

2) the width of horizontal plate (b);

3 ) the corrugation depth $\left(h_{f}\right)$;

4) the corrugation angle $(\theta)$;

5) the height of the corrugated steel web $(\mathrm{H})$. 


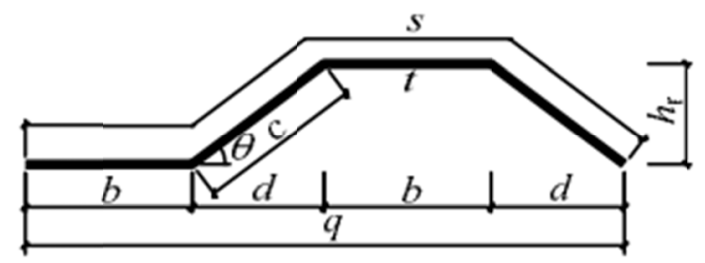

Figure 2. Corrugation Configuration parameters

\subsection{Impact of the Web Thickness ( $t$ )}

To investigate the influence of the web thickness on the ultimate shear buckling load, six girders with the web thickness $\mathrm{t}=6 \mathrm{~mm}, 8 \mathrm{~mm}, 10 \mathrm{~mm}, 12 \mathrm{~mm}, 14 \mathrm{~mm}$ and $16 \mathrm{~mm}$ are taken into account. Other geometric parameters remain unchanged. Ultimate shear buckling load with different web thicknesses are listed in Table 1. Ultimate shear buckling load variation with thicknesses is shown in Figure 3.

Table 1. Ultimate shear buckling load with different web thicknesses

\begin{tabular}{llllllll}
\hline Number & $\mathrm{b} / \mathrm{mm}$ & $\mathrm{d} / \mathrm{mm}$ & $\mathrm{h}_{\mathrm{f}} / \mathrm{mm}$ & $\theta /\left(^{\circ}\right)$ & $\mathrm{H} / \mathrm{mm}$ & $\mathrm{t} / \mathrm{mm}$ & $\begin{array}{l}\text { Buckling load } \\
(\mathrm{Pu} / \mathrm{kN})\end{array}$ \\
\hline T1 & & & & & 6 & 157.27 \\
T2 & & & & & 8 & 209.43 \\
T3 & \multirow{2}{*}{430} & \multirow{2}{*}{550} & \multirow{2}{*}{326.6} & \multirow{2}{*}{30.7} & 5000 & 10 & 262.76 \\
T4 & & & & & & 12 & 320.78 \\
T5 & & & & & 14 & 384.32 \\
T6 & & & & & 16 & 456.46 \\
\hline
\end{tabular}

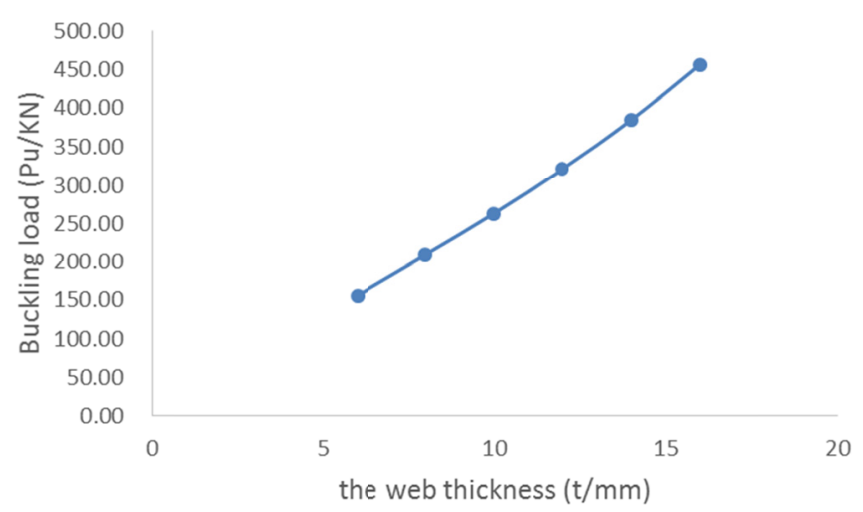

Figure 3. Buckling load variation with thicknesses of corrugated steel web

It is observed in Figure 3 that when the web thickness increases, the ultimate shear buckling load markedly increases. According to the elastic buckling theory, the ultimate shear buckling load is proportional to the 3th power of the web thickness. However, considering the material nonlinearity and geometric nonlinearity, it is obtained that the ultimate shear buckling load do not raise in proportional to the 3 th power of the web thickness.

\subsection{Impact of Horizontal Plate Width (b)}

To investigate the influence of horizontal plate width on the ultimate shear buckling load, six girders with horizontal plate width $\mathrm{b}=330 \mathrm{~mm}, 380 \mathrm{~mm}, 430 \mathrm{~mm}, 480 \mathrm{~mm}, 530 \mathrm{~mm}$ and $630 \mathrm{~mm}$ are taken into account. Other geometric parameters remain unchanged. Ultimate shear buckling load with different widths of horizontal plate are listed in Table 2. Ultimate shear buckling load variation with widths of horizontal plate is shown in Figure 4. 
Table 2. Ultimate shear buckling load with different widths of horizontal plate

\begin{tabular}{|c|c|c|c|c|c|c|c|}
\hline Number & $\mathrm{b} / \mathrm{mm}$ & $\mathrm{d} / \mathrm{mm}$ & $\mathrm{h}_{\mathrm{f}} / \mathrm{mm}$ & $\theta /\left({ }^{\circ}\right)$ & $\mathrm{H} / \mathrm{mm}$ & $\mathrm{t} / \mathrm{mm}$ & $\begin{array}{l}\text { Buckling load } \\
(\mathrm{Pu} / \mathrm{kN})\end{array}$ \\
\hline B1 & 330 & \multirow{6}{*}{550} & \multirow{6}{*}{326.6} & \multirow{6}{*}{30.7} & \multirow{6}{*}{5000} & \multirow{6}{*}{10} & 270.56 \\
\hline B2 & 380 & & & & & & 277.02 \\
\hline B3 & 430 & & & & & & 262.76 \\
\hline B4 & 480 & & & & & & 267.00 \\
\hline B5 & 530 & & & & & & 249.02 \\
\hline B6 & 630 & & & & & & 222.45 \\
\hline
\end{tabular}

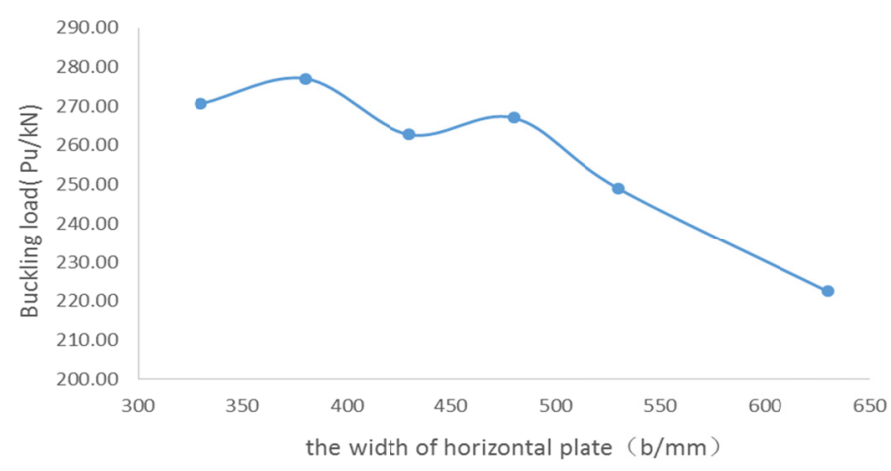

Figure 4. Buckling load variation with widths of horizontal plate

Overall, it can be seen in Figure 4 that the ultimate shear buckling load decreases as horizontal plate width reduces. It is observed that when horizontal plate width increases, the range of buckling deformation decrease and corrugated steel web changes gradually from global buckling to local buckling. Local buckling appears markedly when the width of horizontal plate $b=630 \mathrm{~mm}$. Therefore, it can be seen that the width of horizontal plate has small influence over the ultimate shear buckling load. And in order to make Local buckling does not appear, the width of horizontal plate should not be too large.

\subsection{Impact of the Corrugation Depth $\left(h_{f}\right)$}

To investigate the influence of the corrugation depth on the ultimate shear buckling load, six girders with the corrugation depth $\mathrm{h}_{\mathrm{f}}=237.5 \mathrm{~mm}, 267.2 \mathrm{~mm}, 296.9 \mathrm{~mm}, 326.6 \mathrm{~mm}, 356.3 \mathrm{~mm}$ and $385.9 \mathrm{~mm}$ taken into account. Other geometric parameters remain unchanged. Ultimate shear buckling load with different corrugation depths are listed in Table 3. Ultimate shear buckling load variation with the corrugation depths is shown in Figure 5.

Table 3. Ultimate shear buckling load with different corrugation depths

\begin{tabular}{|c|c|c|c|c|c|c|c|}
\hline Number & $\mathrm{b} / \mathrm{mm}$ & $\mathrm{d} / \mathrm{mm}$ & $\mathrm{h}_{\mathrm{f}} / \mathrm{mm}$ & $\theta /\left(^{\circ}\right)$ & $\mathrm{H} / \mathrm{mm}$ & $\mathrm{t} / \mathrm{mm}$ & $\begin{array}{l}\text { Buckling load } \\
(\mathrm{Pu} / \mathrm{kN})\end{array}$ \\
\hline HF1 & \multirow{6}{*}{430} & 400 & 237.5 & \multirow{6}{*}{30.7} & \multirow{6}{*}{5000} & \multirow{6}{*}{10} & 455.63 \\
\hline HF2 & & 450 & 267.2 & & & & 365.37 \\
\hline HF3 & & 500 & 296.9 & & & & 325.71 \\
\hline HF4 & & 550 & 326.6 & & & & 262.76 \\
\hline HF5 & & 600 & 356.3 & & & & 237.19 \\
\hline HF6 & & 650 & 385.9 & & & & 196.04 \\
\hline
\end{tabular}




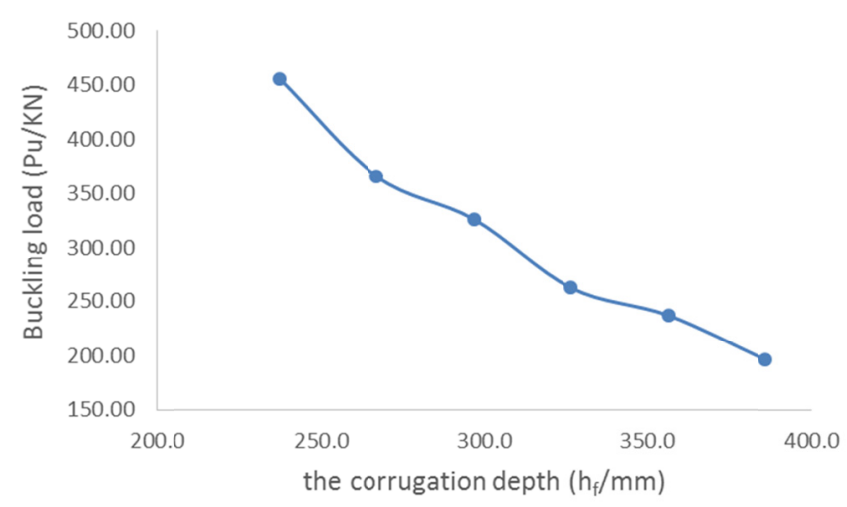

Figure 5. Buckling load variation with the corrugation depths

It is presented in Figure 5 that when the corrugation depth increases, the ultimate shear buckling load decreases. When the corrugation depth changes from $237.5 \mathrm{~mm}$ to $267.2 \mathrm{~mm}$, the ultimate shear buckling load decreases rapidly. Whereas, when the corrugation depth changes from $267.2 \mathrm{~mm}$ to $385.9 \mathrm{~mm}$, the ultimate shear buckling load decreases slowly. It is also observed that as the corrugation depth increases, the width of inclined plate increases and the effect of local buckling is more pronounced. When the corrugation depth is kept constant, the value of the corrugation depth should be determined by the width of horizontal plate and the width of the inclined plate should be less than the width of horizontal plate.

\subsection{Impact of the Corrugation Angle ( $\theta)$}

To investigate the influence of the corrugation angle on the ultimate shear buckling load, six girders with the corrugation angle $\theta=30.7^{\circ}, 40^{\circ}, 45^{\circ}, 50^{\circ}, 55^{\circ}$ and $60^{\circ}$ are taken into account. Other geometric parameters remain unchanged. Ultimate shear buckling load with different corrugation angles are listed in Table 4. Ultimate shear buckling load variation with the corrugation angles is shown in Figure 6.

Table 4. Ultimate shear buckling load with different corrugation angles

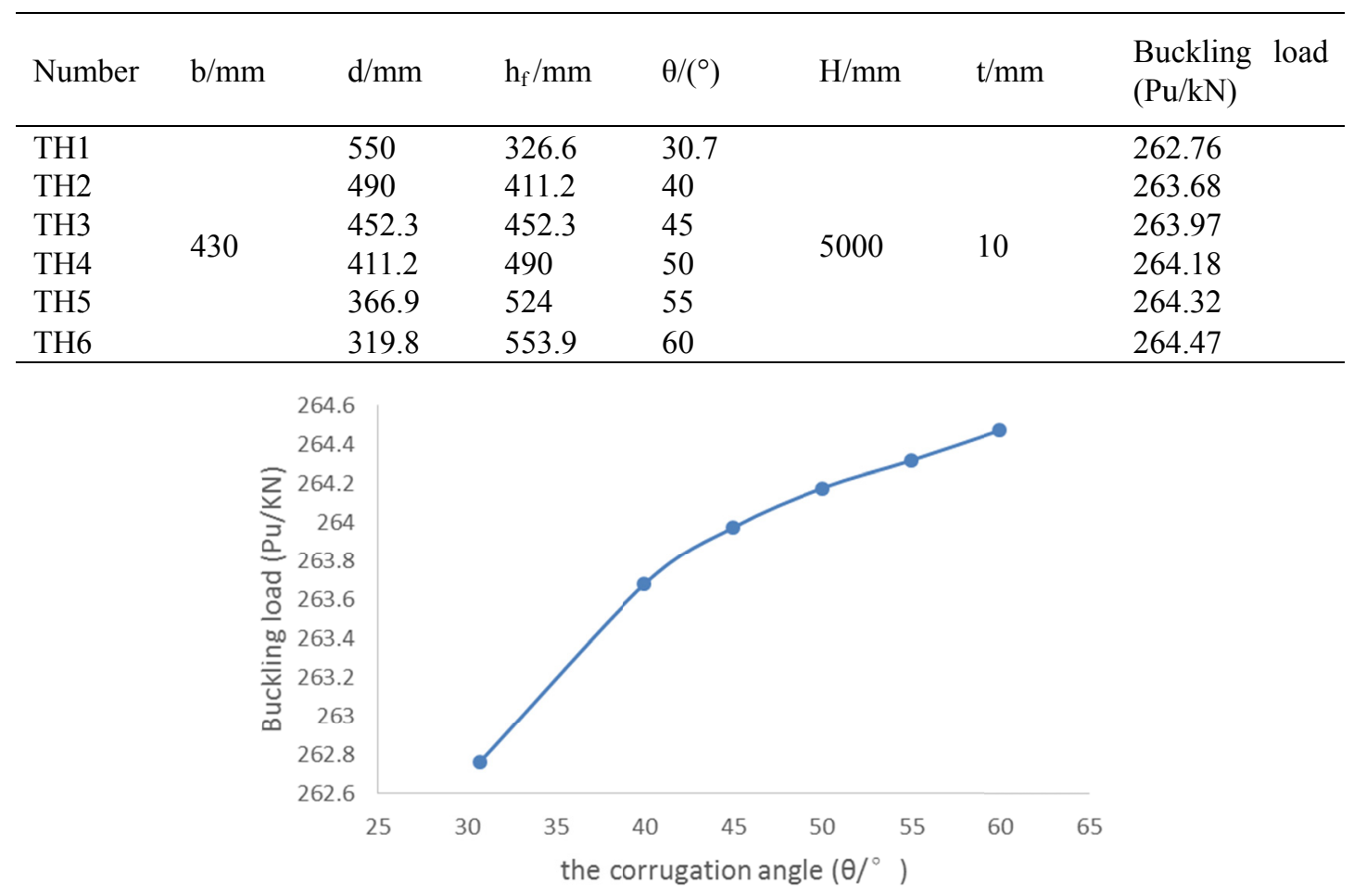

Figure 6. Buckling load variation with the corrugation angles 
It is presented in Figure 6 that when the corrugation angle increases, the ultimate shear buckling load increases slightly. It can be easily known that the corrugation depth raises as the angle of the corrugation increases. Whereas, the ultimate shear buckling load does not decrease as the depth of the corrugation raises. The reason is that the width of the inclined plate is kept constant. In Figure 5, the ultimate shear buckling load decreases as the corrugation depth increases. The root cause is the increase of the inclined plate width which the increase of the corrugation depth cause.

\subsection{Impact of the Corrugated Steel Web Height $(H)$}

To investigate the influence of the corrugated steel web height on the ultimate shear buckling load, six girders with the corrugation steel web height $\mathrm{H}=3000 \mathrm{~mm}, 4000 \mathrm{~mm}, 5000 \mathrm{~mm}, 6000 \mathrm{~mm}, 7000 \mathrm{~mm}$ and $8000 \mathrm{~mm}$ are taken into account. Other geometric parameters remain unchanged. Ultimate shear buckling load with different corrugated steel web heights are listed in Table 5. Ultimate shear buckling load variation with heights of corrugated steel web is shown in Figure 7.

Table 5. Ultimate shear buckling load with different corrugated steel web heights

\begin{tabular}{|c|c|c|c|c|c|c|c|}
\hline Number & $\mathrm{b} / \mathrm{mm}$ & $\mathrm{d} / \mathrm{mm}$ & $\mathrm{h}_{\mathrm{f}} / \mathrm{mm}$ & $\theta /\left(^{\circ}\right)$ & $\mathrm{H} / \mathrm{mm}$ & $\mathrm{t} / \mathrm{mm}$ & $\begin{array}{l}\text { Buckling load } \\
(\mathrm{Pu} / \mathrm{kN})\end{array}$ \\
\hline H1 & \multirow{6}{*}{430} & \multirow{6}{*}{550} & \multirow{6}{*}{326.6} & \multirow{6}{*}{30.7} & 3000 & \multirow{6}{*}{10} & 260.75 \\
\hline $\mathrm{H} 2$ & & & & & 4000 & & 261.32 \\
\hline H3 & & & & & 5000 & & 262.76 \\
\hline H4 & & & & & 6000 & & 264.07 \\
\hline H5 & & & & & 7000 & & 265.12 \\
\hline H6 & & & & & 8000 & & 265.50 \\
\hline
\end{tabular}

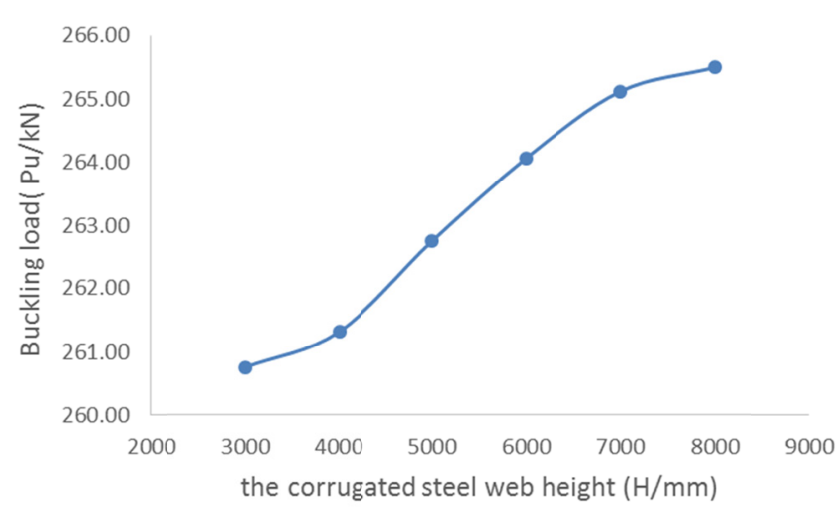

Figure 7. Buckling load variation with heights of corrugated steel web

It is presented in Figure 7 that when the height of corrugated steel web increases, the ultimate shear buckling load increases slightly. This is because the cross-sectional area, which increases as the height of corrugated steel web increases, increases. Accordingly, the ultimate shear buckling load increases. It also can be seen that as the height of corrugated steel web increases, the web will easily be in a local buckling mode. To improve the value of the ultimate shear buckling load for corrugated steel web in relatively height, the width of horizontal plate and the width the inclined plate should properly decrease, or the corrugation angle should properly increase.

\section{Conclusions}

In this paper, the finite element model with corrugated steel webs is built using ANSYS Parametric Design Language (APDL). In the finite element model, the material nonlinearity, geometric nonlinearity and structural defects in the initial geometry have been taken into account. Based on extensive analysis, following conclusions are made:

1) When the web thickness increases, the ultimate shear buckling load significantly increases. Nevertheless, the ultimate shear buckling load do not keep proportional relation with the 3 th power of the web thickness. 
2) Overall, the ultimate shear buckling load of corrugated steel web decreases as horizontal plate width raises.

3) With the same corrugation angle and horizontal plate width, the ultimate shear buckling load of corrugated steel web decreases as the corrugation depth increases. What's more, when the depth of the corrugation raises, the buckling mode in the nonlinear finite element model will change from global buckling mode to local buckling mode.

4) As the corrugation angle increases, the ultimate shear buckling load of corrugated steel web is slightly improved.

5) With the same the corrugated steel web width, the ultimate shear buckling load of corrugated steel web increases slightly as the height of corrugated steel web increases.

\section{References}

Driver, R. G., Abbs, H. H., \& Sause, R. (2006). Shear behavior of corrugated web bridge girders. Journal of $\begin{array}{llll}\text { Structural } \quad \text { Engineering, } & \text { 132(2), }\end{array}$ http://dx.doi.org/10.1061/(ASCE)0733-9445(2006)132:2(195)

Elgaaly, M, Seshadri, A., \& Hamilton, R M. (1997). Bending strength of steel beams with corrugated web. $\begin{array}{lllll}\text { Journal of Structural } & \text { Engineering, } & \text { ASCE, } & 123(6),\end{array}$ http://dx.doi.org/10.1061/(ASCE)0733-9445(1997)123:6(772)

Elgaaly, M., Hamilton, R. M., \& Seshadri, A. (1996). Shear strength of beams with corrugated webs. Journal of $\begin{array}{llll}\text { Structural } \quad \text { Engineering, } & \text { 390-398. }\end{array}$ http://dx.doi.org/10.1061/(ASCE)0733-9445(1996)122:4(390)

Johnson, R. P., \& Cafolla, J. (1997). Corrugated webs in plate girders for bridges. Proceedings of the Institution of Civil Engineers. Structures and Buildings, 122(2), 157-164. http://dx.doi.org/10.1680/istbu.1997.29305

Li, H., Ye, J., Wan, S., Qian, P., \& Jiang, Z. (2004). Experimental research on prestressed concrete box girder with corrugated steel webs. China Journal of Highway and Transport, 17(4), 31-36.

Luo, R., \& Edlund, B. (1996). Shear capacity of plate girders with trapezoidally corrugated webs. Thin-Walled Structures, 26(1), 19-44. http://dx.doi.org/10.1016/0263-8231(96)00006-7

Nie, J., Zhu, L., \& Tang, L. (2013). Shear strength of trapezoidal corrugated steel webs. China Civil Engineering Journal, 46(6), 97-109.

Shan, C. (2008). Buckling analysis of corrugated steel webs in prestressed concrete composite box-girder bridge. Engineering Mechanics, 25(6), 122-127.

Song, J., Zhang, S., \& Lv, J. (2004). Simulation and Impact Analysis for Initial Imperfections in Shear Buckling Analysis for Corrugated Steel Webs. Journal of Highway and Transportation Research and Development, 21(5), 61-64.

\section{Copyrights}

Copyright for this article is retained by the author(s), with first publication rights granted to the journal.

This is an open-access article distributed under the terms and conditions of the Creative Commons Attribution license (http://creativecommons.org/licenses/by/3.0/). 